\title{
Randomized clinical study assessing two membranes for guided bone regeneration of peri-implant bone defects: clinical and histological outcomes at 6 months
}

Naenni, Nadja ; Schneider, David ; Jung, Ronald E ; Hüsler, Jürg ; Hämmerle, Christoph H F ; Thoma, Daniel S

\begin{abstract}
PURPOSE To test whether or not one of two membranes is superior for peri-implant-guided bone regeneration in terms of clinical and histologic outcomes. MATERIAL AND METHODS In 27 patients, 27 twopiece dental implants were placed in single-tooth gaps in the esthetic area. Buccal dehiscence and/or fenestrationtype defects were regenerated using demineralized bovine bone mineral and randomly covered with either a resorbable membrane (RES) or a titanium-reinforced non-resorbable membrane (N-RES). Clinical measurements included vertical defect resolution and the horizontal thickness of regenerated bone at implant placement and at 6 months. Statistics were performed by means of nonparametric testing. RESULTS The remaining mean vertical defect measured $4 \mathrm{~mm}( \pm 2.07)(\mathrm{RES})$ and $2.36 \mathrm{~mm}( \pm 2.09)(\mathrm{N}-\mathrm{RES})(\mathrm{P}=0.044)$ at baseline and $0.77 \mathrm{~mm}( \pm 0.85)(\mathrm{RES})$ and $0.21 \mathrm{~mm}( \pm 0.80)(\mathrm{N}-\mathrm{RES})(\mathrm{P}=0.021)$ at re-entry. This translated into a defect resolution of $85 \%(\mathrm{RES})$ and $90.7 \%$ $(\mathrm{N}-\mathrm{RES})(\mathrm{P}=0.10)$. The horizontal thickness after augmentation measured $3.46 \mathrm{~mm}( \pm 0.52)(\mathrm{RES})$ and $2.82 \mathrm{~mm}$ $( \pm 0.50)(\mathrm{N}-\mathrm{RES})(\mathrm{P}=0.004)$. The mean loss in horizontal thickness from baseline to re-entry measured $2.23 \mathrm{~mm}$ $(\mathrm{SD} \pm 1.21)(\mathrm{RES})$ and $0.14 \mathrm{~mm}( \pm 0.79)(\mathrm{N}-\mathrm{RES})(\mathrm{P}=0.017)$. The horizontal changes in thickness at the implant shoulder level were statistically significant between the groups $(\mathrm{P}=0.0001)$. CONCLUSIONS Both treatment modalities were clinically effective in regenerating bone as demonstrated by a similar horizontal thickness and vertical defect fill at 6 months. The N-RES group exhibited significantly less horizontal bone thickness reduction from baseline to follow-up.
\end{abstract}

DOI: https://doi.org/10.1111/clr.12977

Posted at the Zurich Open Repository and Archive, University of Zurich ZORA URL: https://doi.org/10.5167/uzh-126657

Journal Article

Updated Version

Originally published at:

Naenni, Nadja; Schneider, David; Jung, Ronald E; Hüsler, Jürg; Hämmerle, Christoph H F; Thoma, Daniel S (2017). Randomized clinical study assessing two membranes for guided bone regeneration of peri-implant bone defects: clinical and histological outcomes at 6 months. Clinical Oral Implants Research, 28(10):1309-1317.

DOI: https://doi.org/10.1111/clr.12977 
Randomized clinical study assessing two membranes for guided bone regeneration of peri-implant bone defects: clinical and histological outcomes at 6 months

\author{
Nadja Naenni ${ }^{1}$, David Schneider ${ }^{1}$, Ronald E. Jung ${ }^{1}$, Jürg Hüsler, Christoph H.F. \\ Hämmerle ${ }^{1}$, Daniel S. Thoma ${ }^{1}$
}

Key words: dental implants, bone and bones, bone regeneration, membranes, alveorlar ridge augmentation (all Mesh terms)

Running title: guided bone regeneration using two different membranes

Address for correspondence:

PD Dr. Daniel S. Thoma

Clinic of Fixed and Removable Prosthodontics and Dental Material Science Center of Dental Medicine, University of Zurich

Plattenstrasse 11

$\mathrm{CH}-8032$ Zurich, Switzerland

Phone: +41446343260

Fax: +41446344305

e-mail: daniel.thoma@zzm.uzh.ch

${ }^{1}$ Clinic for Fixed and Removable Prosthodontics and Dental Material Science, Center of Dental Medicine, University of Zurich, Zurich, Switzerland 


\section{Abstract}

Purpose: To test whether or not one out of two membranes is superior for periimplant guided bone regeneration in terms of clinical and histologic outcomes.

Materials and Methods: In 27 patients, 27 two-piece dental implants were placed in single-tooth gaps in the esthetic area. Buccal dehiscence and/or fenestration-type defects were regenerated using demineralized bovine bone mineral (DBBM) and randomly covered with either a resorbable membrane (RES) or a titanium-reinforced non-resorbable membrane (N-RES). Clinical measurements included vertical defect resolution and the horizontal thickness of regenerated bone at implant placement and at 6 months. Statistics were performed by means of non-parametric testing.

Results: The remaining mean vertical defect measured $4.00 \mathrm{~mm}( \pm 2.07)(\mathrm{RES})$ and $2.36 \mathrm{~mm}( \pm 2.09)(\mathrm{N}-\mathrm{RES})(\mathrm{p}=0.044)$ at baseline and $0.77 \mathrm{~mm}( \pm 0.85)(\mathrm{RES})$ and $0.21 \mathrm{~mm}( \pm 0.80)(N-R E S)(p=0.021)$ at re-entry. This translated into a defect resolution of $85 \%$ (RES) and $90.7 \%(N-R E S)(p=0.10)$. The horizontal thickness after augmentation measured $3.46 \mathrm{~mm}( \pm 0.52)(R E S)$ and $2.82 \mathrm{~mm}$ $( \pm 0.50)(N-R E S)(p=0.004)$. The mean loss in horizontal thickness from baseline to re-entry measured $2.23 \mathrm{~mm}(\mathrm{SD} \pm 1.21)(\mathrm{RES})$ and $0.14 \mathrm{~mm}( \pm 0.79)(\mathrm{N}-\mathrm{RES})$ $(p=0.017)$. The horizontal changes in thickness at the implant shoulder level were statistically significant between the groups $(p=0.0001)$.

Conclusions: Both treatment modalities were clinically effective in regenerating bone as demonstrated by a similar horizontal thickness and vertical defect fill at 6 months. The N-RES group exhibited significantly less horizontal bone thickness reduction from baseline to follow-up. 


\section{Introduction}

Guided bone regeneration (GBR) procedures are routinely performed in dental practice to regenerate missing hard tissue volume prior to or simultaneously with dental implant placement (Hammerle et al., 2002, Bornstein et al., 2008, Hammerle and Karring, 1998). Various GBR techniques have been proposed and numerous materials are available to the practitioner (Donos et al., 2008, Esposito et al., 2006, Aghaloo and Moy, 2007, Jensen and Terheyden, 2009, Benic and Hammerle, 2014).

Initially, the GBR technique was developed to regenerate periodontal tissues (Nyman et al., 1982, Gottlow et al., 1984, Gottlow et al., 1986). Later, this technique was also suggested and applied for bone augmentation around dental implants (Jovanovic et al., 1992, Karring et al., 1993). For that purpose autogenous bone or bone substitute materials in combination with non-resorbable barrier membranes were used. The integration of titanium reinforcements into non-resorbable expanded polytetrafluorethylene (ePTFE) membranes increased their stability and allowed the membrane to be formed into an adequate shape. Despite high clinical success rates (Friedmann et al., 2001, von Arx et al., 2001, Buser et al., 2002), ePTFE membranes exhibit two main clinical disadvantages: i) an additional surgery procedure is necessary to remove the membrane; ii) increased rates of membrane exposure leading to impaired wound healing, especially during the early healing phase (Piette et al., 1995, Moses et al., 2005) and, bacterial colonization with subsequent infection of the augmented site (Becker et al., 1994, Simion et al., 1994, Strietzel, 2001).

In order to overcome these shortcomings, resorbable membranes were introduced. Among these, collagen membranes are well documented and render high clinical success rates (Pitaru et al., 1987, Zitzmann et al., 1997, Hockers et al., 1999, Zitzmann et al., 2001a, Friedmann et al., 2001, Hammerle and Lang, 2001, Hammerle et al., 1998). However, these relatively soft membranes do not 
maintain space per se and a compression of the regenerated site can potentially result in a displacement of the augmentation material (Strietzel et al., 2006, Friedmann et al., 2002)

To date, there is weak evidence with respect to the morphological changes of the augmented tissues following GBR procedures around dental implants. A variety of studies focused on the stability of the mucosal margin (Jemt et al., 2006, Priest, 2003, Grunder, 2000) and the height of the papilla around implant-supported crowns (Cardaropoli et al., 2006, Chang et al., 1999). However, the changes of contour and morphology of the labial peri-implant tissues have not been investigated in detail (Jemt et al., 2006, Jemt and Lekholm, 2003) until recently (Jensen et al., 2014, Schneider et al., 2014).

The aim of the present study was to test whether or not one of two GBR membranes is superior to the other in terms of: i) vertical defect resolution and bucco-oral width of regenerated bone at the implant shoulder at 6 months ii) postoperative complications during the 6-month follow-up and, iii) histologically assessed mineralized tissue at 6 months. 


\section{Materials and methods}

This study was designed as a prospective randomized controlled clinical trial. All procedures and materials were approved by the local ethical committee ( $\mathrm{Nr}$. 2010-0051/5). Twenty-seven patients with a single tooth gap (central incisor to premolar in the maxilla or mandible) in need of implant treatment were consecutively recruited at the Clinic of Fixed and Removable Prosthodontics and Dental Material Science, Center of Dental Medicine, the University of Zurich, Switzerland. Informed consent was obtained from all patients prior to the start of the study. The following inclusion criteria were applied:

1. Periodontally healthy patients (periodontal probing depths $<4 \mathrm{~mm}$ )

2. Good oral hygiene (full mouth plaque index <25\%) (O'Leary et al., 1972)

3. Adequate control of inflammation (full mouth bleeding on probing $<25 \%$ (Ainamo and Bay, 1975)

4. Single tooth gaps with a buccal alveolar bone deficiency

5. Planned implant placement $>6$ weeks after tooth extraction

6. A dehiscence or fenestration-type defect after implant placement Patients not meeting all inclusion criteria were not enrolled prior to surgery (1-5) or excluded from the study after implant placement (6).

Enrolled patients were scheduled for a baseline visit. This examination encompassed the following assessments: clinical periodontal parameters (periodontal probing depth (PPD), plaque control record (PCR), bleeding on probing (BOP), all at six sites around the adjacent teeth; the width of keratinized tissue (KM) on the buccal side of the two neighboring teeth, a conventional impression (President, Coltène/Whaledent, Altstätten, Switzerland) and clinical photographs of the planned implant site. Two to 4 weeks after the baseline visit, implant surgery was performed. 


\section{Surgical protocol}

Prior to the start of the surgery, patients had to rinse with a $0.2 \%$ Chlorhexidine solution for one minute and were given antibiotics (Amoxicillin 750mg, Sandoz Pharmaceuticals, Risch, Switzerland) and analgesics (Mefenacid 500mg, Mepha Pharma AG, Basel, Switzerland). Local anesthesia was achieved with Articaine hydrochloride (Rudocaine forte ${ }^{\circ}$, Streuli, Switzerland). Following an intrasulcular incision around the two neighbouring teeth and a vertical releasing incision at the disto-buccal aspect of the distal neighboring tooth a mucoperiosteal flap was raised. The implant site was prepared according to the manufacturers recommendations and a screw type, rough surface two-piece dental implant (OsseoSpeed, ASTRA TECH Implant System, DENTSPLY Implants, Mölndal, Sweden) was placed in a prosthetically ideal position using a surgical stent. Implants had to reach primary stability. Subsequently, the peri-implant osseous defect was measured using a calibrated periodontal probe (PCP-11, Hu-Friedy, Chicago, USA). Clinical measurements included defect height, depth, width and infrabony defect size (Fig.1). If no bone defect was present and no bone augmentation was needed, the patient was excluded from the study.

Simultaneous GBR was performed using demineralized bovine bone mineral (DBBM, BioOss spongiosa granules, particle size 0.25-1.0mm; Geistlich Pharma AG, Wolhusen, Switzerland). At this time-point according to a computergenerated randomization list and using sealed envelopes (prepared by the study monitor), either one of two membranes was applied:

i) resorbable collagen membrane (BioGide, Geistlich Pharma AG, Wolhusen, Switzerland) (RES)

ii) non-resorbable ePTFE-membrane (Gore-Tex®, W.L. Gore \& Assoc., Flagstaff, Arizona, USA) (N-RES)

The peri-implant defect and the missing hard tissue contour were built up with DBBM particles. The horizontally augmented thickness on the buccal side was 
measured at the level of the implant shoulder (Fig.1). In group RES, the resorbable membrane was cut to fit the osseous defect covering the respective bone regenerate. Two to three resorbable pins made of polylactic acid (Inion Pins; Geistlich AG, Wolhusen, Switzerland) were then used to tack the membrane buccally onto the underlying bone to avoid membrane and DBBM displacement. In group N-RES, the ePTFE-membrane was extraorally shaped and adapted to fit the defect size. Non-resorbable titanium pins (Frios ${ }^{\circledR}$, Friadent $\mathrm{GmbH}$, Mannheim, Germany) were used to stabilize the membrane. Both membranes had to overlap the borders of the augmented site defect by at least $2 \mathrm{~mm}$. On the palatal/lingual aspect the membranes were placed under the flap. Subsequently, releasing incisions within the periosteum were performed on the buccal aspect of the flap to allow for a tension-free wound closure. Primary wound closure was obtained using non-resorbable sutures (Gore-Tex suture; Gore, Flagstaff, AZ, USA).

The patients were then instructed to refrain from mechanical plaque removal in the surgical area for 7-10 days and had to follow a strict postoperative regimen. This consisted of rinsing with an aqueous solution of $0.2 \%$ chlorhexidine (Kantonsapotheke, Zurich, Switzerland), of a medication with antibiotics for 5 days (Amoxicillin 750mg, Sandoz Pharmaceuticals, Risch, Switzerland) and analgesics (Mefenacid 500mg, Mepha Pharma AG, Basel, Switzerland) according to individual needs.

\section{Follow-up visits}

Suture removal was performed 7-10 days after implant placement. Patients were then recalled at 4 weeks, at 3 and at 6 months to assess the soft tissue condition (normal, swollen, red, dehiscence). In addition, a conventional impression (President, Coltène/Whaledent, Altsätten, Switzerland) and clinical photographs of the implant sites were taken at each time-point. At 6 months, re-entry surgery was performed in all patients by elevating a full thickness flap to again measure 
the vertical defect fill and the horizontal thickness of the bone at the buccal aspect of the implant with a calibrated periodontal probe (PCP-11, Hu-Friedy, Chicago, USA). These measurements were performed at the level of the implant shoulder. In addition, core-biopsies were harvested using a trephine bur with an inner diameter of $1.8 \mathrm{~mm}$. The biopsies were performed at a level of $3 \mathrm{~mm}$ below the implant shoulder perpendicular to the long axis of the implant with a sink depth of $3 \mathrm{~mm}$ (Figure 3 ). The cover screw was removed and replaced by a healing abutment. The mucoperiosteal flap was adjusted and sutured to fit around the neck of the healing abutment. If a buccal concavity was persisting at this time-point, a soft tissue grafting procedure (Seibert, 1983, Schneider et al., 2011, Thoma et al., 2016) was performed and implants left submerged for another 2 months before performing abutment connection.

\section{Histologic preparation and analyses}

The biopsies were fixed in $4 \%$ buffered formalin for at least 48 hours. The specimens were then rinsed in running tap water and demineralized for 72 hours (USEDECALC BioSystems, Muttenz, Switzerland). After decalcification they were watered again for 1 hour and dehydrated in a graded series of increasing ethanol concentrations and thereafter infiltrated with xylol and paraffin in a vacuum infiltration tissue processor (Tissue-Tek VIP, Sakura-Finetek, Torrance, CA/USA). Specimens were then embedded in paraffin and cut into $2-5 \mu \mathrm{m}$ thickness using a paraffin-microtome (MICROM, Medite $\mathrm{GmbH}$, Dietlikon, Switzerland). The specimens were dried with warm air (Wärmeschrank, Bittmann, Basel, Switzerland), de-paraffinized with xylol and stained with Haemalaun-Eosin (Robert Hooke 1665, Böhmer 1865).

A qualitative analysis was performed with a light-microscope (Leica CTR6000, Leica, Wetzlar, Germany) at a magnification of $\times 200$. Pictures of each specimen were taken with a camera attached to the microscope (Leica DFC450, Leica, 
Wetzlar, Germany) for further analysis. All available sections were quantitatively assessed for different tissue components by applying standard histological morphometrical techniques (Weibel 1980; Gundersen et al. 1988). The different components (background, non-mineralized tissue, mineralized tissue and bone substitute material) and their respective amount calculated in \% within a central region of interest. Measurements were carried out using an image analysis software (LAS V4.3, Leica, Wetzlar, Germany).

\section{Statistical evaluation and analysis}

Outcome measures

The following primary and secondary outcome variables were analyzed:

Primary: vertical defect fill (dehiscence defect at the buccal aspect of the implant)

Secondary: horizontal thickness of the regenerated bone at the buccal aspect of the implant; defect depth, defect width and infrabony defect height; soft tissue condition (dehiscences); clinical parameters (PPD, PCR, BOP,KM), histomorphometric outcome measures (percentage of newly formed bone, remaining amount of bone substitute material, bone substitute to bone contact)

\section{Sample size calculation}

The sample size was calculated according to a previously performed study using similar primary and secondary endpoints (Jung et al., 2009). As the primary endpoint of this study was the vertical defect fill, it was planned to recruit a total number of 34 patients (17 per group). This would enable to detect a difference of $1 \mathrm{~mm}$ between the test and control group with a standard deviation of $\sigma=1$ and a significance level of $\alpha=0.05$ with a power of $80 \%$.

Descriptive statistics were applied to the data. Statistical analysis of the most important questions was based on non-parametric tests because of small sample 
sizes. Significance were determined using the Wilcoxon Mann-Whitney U-test with SAS 9.4. The level of significance was set at $P<0.0083$ since 6 tests (hypotheses) were applied for the 6 primary questions (by Bonferroni correction). A p-value between 0.05 and 0.0083 may be considered as a borderline significance pointing on a possible difference. Mean and standard deviations are given in the following section. In the tables medians are reported which are analyzed by the nonparametric tests. For analysis of possible confounders a robust mixed model approach (with the R Package pbkrtest) was applied to a part of the data. All the other tests were used as explorative investigations. 


\section{Results}

\section{Demographics}

Eligible patients were enrolled between March 2010 and January 2013. 55

patients were initially screened. Finally, a total of 27 patients could be randomized for treatment and included in the study (14 female, 13 male). All patients were in good general health and had previously undergone comprehensive dental care. They were all followed up to 6 months after implant placement. Thirteen patients were randomized for group RES and 14 patients for group N-RES. Seven implants were placed in the mandible, whereas 21 implants were placed in the maxilla. The exact distribution of implant sites and locations is depicted in Table 1.

The mean age was 51.85 years (standard deviation \pm 29.7 ). Six patients were light smokers ( $\leq 10 \mathrm{cig} /$ day) and three patients had a history of periodontitis.

\section{Defect dimensions at implant placement and at re-entry}

All data for defect width, defect depth and infrabony defect size are displayed in Table 2a. Results for defect width and depth were statistically significant or borderline for the time-point $(p=0.0001 / p=0.003)$ but did not show effect of group interaction in the more complex mixed model.

The mean vertical defect height after implant placement measured $4.00 \mathrm{~mm}$ $( \pm 2.07)$ in group RES and $2.36 \mathrm{~mm}( \pm 2.09)$ in group N-RES. At 6 months, the mean remaining vertical defect height measured $0.77 \mathrm{~mm}( \pm 0.85)(\mathrm{RES})$ and $0.21 \mathrm{~mm}( \pm 0.80)(\mathrm{N}-\mathrm{RES})$. Table $2 \mathrm{~b} \& \mathrm{c}$

Differences between the two groups were statistically borderline significant at both time-points $(p=0.044 / p=0.021)$. Mean changes in vertical defect height from baseline to 6 months measured $3.41 \mathrm{~mm}( \pm 2.33)$ (RES) and $2.14 \mathrm{~mm}$ $( \pm 2.06)(N-R E S)(p=0.1069)$. Table $2 b \& c$ This amounted to a vertical defect resolution of $85 \%$ (RES) and $90.7 \%$ (N-RES). 
Seven sites (6 RES / 1 N-RES) demonstrated incomplete vertical regeneration, whilst one site in group RES even showed an increased vertical defect height at re-entry compared to baseline (after implant placement).

The mean horizontal thickness at the level of the implant shoulder measured $3.46 \mathrm{~mm}( \pm 0.52)(\mathrm{RES})$ and $2.82 \mathrm{~mm}( \pm 0.50)$ (N-RES) following grafting with $\operatorname{DBBM}(p=0.0040)$. At 6 months, the mean horizontal thickness was $1.32 \mathrm{~mm}$ ( \pm 1.38) (RES) and $2.68 \mathrm{~mm}( \pm 1.05)(\mathrm{N}-\mathrm{RES})(p=0.0167)$. Both groups showed a loss of horizontal thickness over time with a mean of $2.23 \mathrm{~mm}( \pm 1.21)$ (RES) and $0.14 \mathrm{~mm}( \pm 0.79)(\mathrm{N}-\mathrm{RES})$. The differences between the groups were statistically significant $(p=0.0001)$ See Table $2 b \& c$.

\section{Soft tissue condition}

Although primary wound closure was obtained in all patients, a total of six dehiscences (local adverse event) were observed during the 6-month follow-up. Four dehiscences were observed in group RES (30\%) and two in group N-RES (14\%). Five dehiscences were present at the time of suture removal. Four of these occurred in the RES group and healed spontaneously until the 4-week follow-up. One dehiscence in the N-RES group healed between the 4-week and 3month follow-up. The second dehiscence in the N-RES group occurred between suture removal and the 4-week follow-up. This patient was advised to apply local disinfecting agents (Plak Out Gel, Kerr Hawe SA, Bioggio, Switzerland and Solcoseryl, Meda Pharma GmbH, Wangen-Brüttisellen, Switzerland) and was recalled once a week for four weeks and later on once a month. The dehiscence persisted until the re-entry surgery at 6 months.

The number of dehiscences at the different time-points is displayed in Table $3 a$. The soft tissue condition at re-entry is displayed in Table 3b. Overall, in all but one patient, the soft tissues were rated "normal" at 3 and 6 months after implant surgery. 


\section{Clinical parameters}

Probing Pocket Depth (PPD)

Mean PPD values varied between $2.27 \mathrm{~mm}( \pm 0.45 \mathrm{~mm}$; mesially $)$ and $2.38 \mathrm{~mm}$ $( \pm 0.44 \mathrm{~mm}$; distally) in group RES and $2.34 \mathrm{~mm}( \pm 0.29 \mathrm{~mm} ; \mathrm{mes})$ and $2.50 \mathrm{~mm}$ $( \pm 0.42 \mathrm{~mm}$; dis $)$ in group N-RES. At 6 months PPD values measured $2.24 \mathrm{~mm}$ $( \pm 0.32 \mathrm{~mm} ; \mathrm{mes})$ and $2.44 \mathrm{~mm}( \pm 0.47 \mathrm{~mm}$; dis) for the RES group and $2.36 \mathrm{~mm}$ $( \pm 0.25 \mathrm{~mm} ; \mathrm{mes})$ and $2.42 \mathrm{~mm}( \pm 0.35 \mathrm{~mm} ; \mathrm{dis})$. Results were statistically not significant for neither mesial/distal aspect, nor between the groups and at the two time points $(p>0.05)$.

Plaque control record (PCR)

Plaque indices at time-point before implant placement and at 6 months did not show to be statistically significant when compared over time. No statistically significant differences were measured between the two groups.

\section{Bleeding-on-probing (BOP)}

BOP values did not show to be statistically significant over time for mesial values, but decreased over time for the distal values. These were statistically borderline significant $(p=0.04)$.

\section{Keratinized Tissue (KM)}

The width of keratinized tissue decreased between screening (prior to surgery) and 6 months from $4.1 \mathrm{~mm}$ (SD 0.77 ; mesial) and $4.0 \mathrm{~mm}( \pm 0.43$; distal) to $3.4 \mathrm{~mm}( \pm 0.47$; mesial $)$ and $2.9 \mathrm{~mm}( \pm 0.26$; distal $)$ in group RES. The corresponding values for group N-RES were $4.3 \mathrm{~mm}( \pm .04 ;$ mesial $)$ and $4.2 \mathrm{~mm}$ ( \pm 0.2 ; distal) pre-surgically and decreased to $3.8 \mathrm{~mm}( \pm 0.3 ;$ mesial $)$ and $3.6 \mathrm{~mm}$ $( \pm 0.3 ;$ distal $)$ at 6 months. For both groups the differences over time were borderline statistically significant $(P=0.03)$. 
Histologic assessment

In general, the histologic samples revealed loose DBBM particles surrounded to a large extent by newly formed bone and embedded in a loose connective tissue. Remodeling of the DBBM particles had taken place and led to the formation of vacuoles with intimate bone formation along the bone substitute surface. (Fig.4) The density of the DBBM particles and the newly formed bone as well as the density of the connective tissue demonstrated great variation within the groups. The histomorphometric analysis showed a mean amount of newly formed bone of $38.0 \%( \pm 18.4 \%)($ RES $)$ and of $35.7 \%( \pm 29.5 \%)(N-R E S)$. The remaining amount of DBBM was $36.4 \%( \pm 8.3 \%)($ RES $)$ and $45.2 \%( \pm 11.9 \%)(N-R E S)$ revealing a slightly better containment of the augmented bone substitute material in group N-RES. The overall mean amount of mineralized tissue was $73.0 \%( \pm 19.9 \%)$ (RES) and $69.6 \%( \pm 16.7 \%)(\mathrm{N}-\mathrm{RES})$. The surface fraction of bone substitute to bone contact measured calculated bone to bone substitute contact was $46.4 \%$ $( \pm 25.3 \%)($ RES $)$ and $41.1 \%( \pm 19.1 \%)(N-R E S)$. The differences between the two groups were not statistically significantly different for any of the histological assessments $(p>0.05)$. 


\section{Discussion}

The results of the present RCT demonstrated that i) both GBR membranes were successful in regenerating bone on the buccal side of dental implants regarding vertical defect fill and increase in horizontal thickness; ii) the horizontal thickness decreased to a significantly greater amount over time in group RES compared to group N-RES; iii) wound dehiscences occurred at a rate of $30 \%$ (RES) and $14 \%$ (N-RES), but healed with one exception during 6 months and without the need for premature removal of the membrane; iv) the augmented DBBM underwent remodeling processes and promoted new bone formation.

Augmentation of hard tissue simultaneous with implant placement is considered a routine procedure with successful short- and long-term results (Chiapasco and Zaniboni, 2009, Jung et al., 2013, Hammerle et al., 2002). This is demonstrated by survival rates of implants placed in regenerated bone being similar when compared to implants placed conventionally into sites without the need for bone augmentation (Hammerle et al., 2002, Donos et al., 2008). Differences between resorbable and non-resorbable membranes mainly exist in terms of a need for a second stage surgery (removal of a non-resorbable membrane), a reported higher rate of dehiscences (non-resorbable membranes) and a higher risk of a membrane collapse (resorbable membranes) (Zitzmann et al., 1997, Wiltfang et al., 1998, Moses et al., 2005).

In the present study, peri-implant defect dimensions were re-assessed 6 months after GBR procedure. Defect height, width and depth were all significantly lower at the re-entry time-point compared to the day of implant placement with simultaneous GBR. This demonstrated a successful bone augmentation in both groups with mean changes over time (defect resolution) ranging between 3.41 mm (RES) and $2.14 \mathrm{~mm}(\mathrm{~N}-\mathrm{RES})$ and a very minimal persisting defect height remaining at reentry $(0.77 \mathrm{~mm}$ (RES) and $0.21 \mathrm{~mm}(\mathrm{~N}-\mathrm{RES}))$. The difference in 
decrease was statistically significant between the groups. This is supported by a clinical multicenter study reporting a significant decrease in surface exposure when non-resorbable membranes were used for the treatment of fenestration or dehiscence-type defects (Dahlin et al., 1995). The remaining defect heights after healing periods of 3-6 months measured $1.1 \mathrm{~mm}( \pm 2.3)$ after an initial defect height of $4.7 \mathrm{~mm}( \pm 3.0)$ and were therefore slightly greater compared to the present study. Data on resorbable collagen membranes used in studies with a similar design reported dehiscence-type defect resolution for the combination of DBBM plus collagen membrane of $96 \%$ ( $4.25 \mathrm{~mm}$ from $4.5 \mathrm{~mm}$ ) (Jung et al. 2009) and $91 \%(5.4 \mathrm{~mm}$ from $5.8 \mathrm{~mm}$ ) (Jung et al. 2003), whereas in the present study defect resolution amounted to $85 \%$ (RES) and $90 \%$ (N-RES) respectively. In contrast, in a previous comparative study mean percentages of bone fill of $92 \%$ for resorbable and $78 \%$ for non-resorbable membranes were reported favoring the use of resorbable collagen membranes. However, in that study the relatively high rate of membrane exposure with non-resorbable membranes often led to premature removal due to infection. This was interpreted as the main reason for the lower defect fill for this type of membrane. (Zitzmann et al., 1997). In the present study, even though dehiscences occurred, no membranes were removed prior to the 6-month re-entry time-point. In addition, dehiscences were not associated with greater residual defect heights.

Apart from the defect resolution, which reflects how well a GBR procedure performed in a vertical dimension, the horizontal thickness, measured at baseline (following GBR) and at re-entry surgery, documents the stability of the augmented area. The GBR principle is based on a membrane, which serves as a tent to allow for bone regeneration underneath. This space-maintenance can be obtained using a form-stable membrane or a bone substitute material that stabilizes a non-form-stable membrane. Since in the present study the same bone substitute material was used in both groups, the effect of the membrane in 
terms of stability and containment of the augmented area could be assessed. The horizontal thickness at baseline was greater in group RES compared to group NRES. At re-entry, however, the horizontal thickness in group N-RES was greater. Whereas in both groups, a loss of horizontal thickness was observed, the loss in group N-RES was statistically significantly smaller. This demonstrates that the collagen membrane tended to collapse even though being supported by the bone substitute material.

It has previously been reported that in order to avoid vertical bone loss over time, a minimal buccal bone dimension of $2 \mathrm{~mm}$ is required (Spray et al., 2000, Botticelli et al., 2004). One might speculate that for a successful GBR $2 \mathrm{~mm}$ of buccal bone should be obtained. Keeping in mind these data and the loss of volume that predominantly occurred with the resorbable membrane, a buccal over contouring at the day of surgery might be recommended. The long-term fate of augmented bone and the optimal amount of bone required for stable results remains unknown today. More recent data even suggest that in cases with missing buccal bone on the implant surface, the peri-implant soft tissues might compensate and provide clinically successful outcomes (Benic et al., 2012, Kuchler et al., 2015).

In the present study the number of wound dehiscences was comparable to results reported in previous studies using the same membranes (Moses et al., 2005). Though more dehiscences occurred in group RES (30\%) than in group N-RES $(14 \%)$. This to some extent contradicts results from previous studies with rates for dehiscences ranging from $11 \%$ (Dahlin et al., 1995) to $20 \%$ for nonresorbable membranes (Chiapasco and Zaniboni, 2009) compared to rates ranging between $5 \%$ (Chiapasco and Zaniboni, 2009) and 31\% for resorbable membranes (Jung et al., 2009). Most studies however, observed more dehiscences with non-resorbable membranes compared to resorbable membranes (Moses et al., 2005, Zitzmann et al., 1997). Dehiscences of non-resorbable 
membranes may lead to early removal of the membrane resulting in impaired bone regeneration. In contrast to previously published data (Moses et al., 2005) dehiscences in the present study were not associated with obtained residual defect heights at 6 months. In addition, the two membranes in group N-RES that had a dehiscence, did not have to be removed prematurely. Due to the strict application of local desinfecting agents the respective sites could be prevented from bacterial colonization of the underlying membrane. Similarly, membranes in group RES with dehiscences healed without the need for further surgical intervention. One explanation that might be associated with the number of dehiscences could be the incision design and handling of the flap.

(Dahlin et al., 1995). In the present study the incision design was standardized and did not depend on the randomization. Incisions were made paracrestal (palatally or lingually) in order not to compromise blood supply. Subperiosteal incisions were made to allow for a tension-free adaptation of the wound margins. Moreover, a factor certainly contributing to the low numbers of wound dehiscences is a strict maintenance program. All patients in this study were recalled regularly for a check-up at set time-points, reinstructed for oral hygiene and supported by a professional cleaning. This was reflected in PCR values being stable and BOP values even decreasing over time up to 6 months. Another explantation for the higher number of dehiscences within RES group might be the following. Being aware of having to prematurely remove non-resorbable membranes in case of bacterial colonization, one may have tried not to overcontour the augmentation. It could well be assumed that in order to compensate for the horizontal resorption the surgeons augmented the sites within RES group to a greater extent. This is maybe reflected by a higher amount in horizontal thickness after GBR of $3.46 \mathrm{~mm}$ (RES) versus 2.82 (N-RES).

Although clinical evidence clearly shows the successfull use of e-PTFE membranes for bone regeneration procedures, dehiscences do occur quite often and may compromise the surgical outcome (Zitzmann et al., 1997, Moses et al., 2005). A 
possible reason for the vulnerability of these membranes towards microbial invasion in case of early exposure might be their macroporosity allowing for bacterial colonization of the membrane and thus leading a subsequent infection. As an alternative to the use of e-PTFE, non-expanded, a dense polytetrafluoroethylene (n-PTFE) was proposed due to its inherent characteristics. Most of the available literature on the use of n-PTFE is based on pre-clinical studies. Clinical studies are limited to case series only. Clinical procedures having been investigated including ridge preservation techniques or the placement of immediate implants with concomittant GBR procedures. Whether or not n-PTFE membranes can be successfully used for GBR procedures remains to be proven. (Carbonell et al., 2014)

Both membranes contained the augmented DBBM to a similar extent as demonstrated by small standard deviations in both groups. In terms of bone regeneration, great variability was observed between the different sites. The calculated area fractions of newly formed bone range between $4 \%$ and $63 \%$ (RES) and $11 \%$ and $98 \%$ (N-RES). This rather high heterogeneity in between the sites is mostly due to the fact that in some biopsies, the obtained tissues contained a very loose and only slightly mineralized structure with DBBM particles being surrounded by a loose connective tissue. Since biopsies were taken superficially at the buccal aspect, some of the GBR material might not have been completely integrated and might therefore explain these differences. This is in agreement with a previous clinical study comparing a hydrogel membrane to the same collagen membrane used in the present study (Jung et al., 2009). In that study, a similar re-entry surgery at 6 months was performed and revealed a quality of newly formed bone that ranged from very dense to more soft bone. Previous studies on peri-implant GBR with harvested biopsies reported similar clinical observations (Zitzmann et al., 1997, Jung et al., 2009). Histologic data from biopsies taken 6 months after augmentation surgery with DBBM plus collagen membrane reported newly formed bone between $23 \%$ (Zitzmann et al., 
2001b) and 30\% (Jung et al., 2003) and 39\% for DBBM plus non-resorbable membrane (Friedmann et al., 2002). The mean amounts of newly formed bone in the present study were slightly higher with $38 \%$ (RES) and 36\% (N-RES) within a similar observation period.

The outcomes of the study certainly need to be interpreted with caution. This is mainly due to an imbalance in terms of the initial defect dimension that differed significantly or were borderline after implant placement. Applying the more complex mixed model, however, no effect of group interaction was demonstrated. Moreover, the distribution of sites for the two groups was imbalanced. This shortcoming was due to the nature of the randomization process that took place immediately after implant placement. This might have impacted the outcomes at 6 months. Interestingly, at 6 months, the differences were from a clinical point of view negligible (even though for some outcomes measures statistically significant). Overall, a high number of patients did not fullfill the inclusion criteria. This was due to the need for primary bone augmentation or a lack of dehiscence after implant placement. If a GBR was applied on the buccal side of the implant only for contour reasons, the patient was not included in the study. Furthermore, the production of the non-resorbable e-PTFE membranes was discontinued and they were not available for use after the inclusion of 27 patients. This unfortunately lead to the termination of the recruitment phase and thus did not allow including more patients in this RCT. Still, other non-resorbable membranes were put on the market and are available for clinical use today. Therefore, further follow-up examinations will be performed evaluating longer term outcomes and trying to answer the question whether or not bone regenerated using resorbable or non-resorbable membranes around dental implants can be maintained over time. 


\section{Conclusions}

Guided bone regeneration for buccal dehiscence and fenestration-type defects can be achieved using either membrane. This was demonstrated by a similar vertical defect resolution and a similar horizontal thickness at 6 months in both groups. As collagen membranes do not maintain space and thus tend to collapse, the decrease in horizontal thickness was significantly different in favor of the non-resorbable membrane group at 6 months. Wound dehiscences occurred at a relatively high frequency in both groups, but were not associated with residual vertical defect height at 6 months. Histologically, both membranes allowed for new bone formation and contained a similar amount of bone substitute material during 6 months. 


\section{Acknowledgements}

The study was supported by the Clinic of Fixed and Removable Prosthodontics and Dental Material Science, University of Zurich, Switzerland and by a research grant from the Swiss Dental Association (SSO), Bern, Switzerland. In addition, dental implant materials were provided free of charge by Dentsply (DENTSPLY Implants, Mölndal, Sweden), whereas bone substitute materials and membranes were provided by Geistlich Pharma AG, Wolhusen, Switzerland. The authors do not report to have any conflict of interest to any products related to this study.

The authors are grateful to Mrs. Gisela Müller, study monitor at the Clinic for Fixed and Removable Prosthodontics and Dental Material Science, University of Zurich, Switzerland for her support with the data preparation for the statistical analysis and her support during the preparation of the manuscript. The authors would also like to address gratitude to Ms. Sonja Hitz, Clinic of Fixed and Removable Prosthodontics and Dental Material Science, University of Zurich for the preparation of the histologic slides. Thanks also go to Dr.Caroline Lustenberger for her support in the statistical analysis of the collected data. 


\section{Figure Legends}

Figure 1

Clinical measurements performed during implant surgery and at re-entry (6 months).

Figure 2

Treatment groups with respective membrane. Collagen membrane in resorbable group (RES) and ePTFE-membrane in non-resorbable group (N-RES).

Figure 3

Clinical picture of a site at the time of re-entry 6 months after implant placement and GBR. A trephine bur with an inner diameter of $1.8 \mathrm{~mm}$ is used to harvest the biopsy at $3 \mathrm{~mm}$ below the implant shoulder perpendicular to the long axis of the implant with a sink depth of $3 \mathrm{~mm}$.

Figure 4

Histological sample harvested with a trephine bur with the respective amounts of: 1 ) bone substitute material (DBBM), 2) newly formed bone and 3) soft tissue.

Table 1

Distribution of implant sites and locations in both groups.

Table $2 \mathrm{a} / \mathrm{b} / \mathrm{c}$

Bone defect dimensions and horizontal thickness in millimeters at surgery and after 6 months. Mean values, standard deviations and medians ( $p$-value of the R-test and Wilcoxon Mann-Whitney test 2b/c).

Table $3 a / b$

$3 a$ Number of soft tissue dehiscences at the different time points of assessment. $3 \mathrm{~b}$ Soft tissue condition at the 6-month re-entry (normal/red/swollen/dehiscence). 


\section{References}

Aghaloo, T. L. \& Moy, P. K. (2007) Which hard tissue augmentation techniques are the most successful in furnishing bony support for implant placement? International Journal of Oral and Maxillofacial Implants 22 Suppl, 49-70.

Ainamo, J. \& Bay, I. (1975) Problems and proposals for recording gingivitis and plaque. International Dental Journal 25, 229-235.

Becker, W., Dahlin, C., Becker, B. E., Lekholm, U., van Steenberghe, D., Higuchi, K. \& Kultje, C. (1994) The use of e-PTFE barrier membranes for bone promotion around titanium implants placed into extraction sockets: a prospective multicenter study. International Journal of Oral and Maxillofacial Implants 9, 31-40.

Benic, G. I. \& Hammerle, C. H. (2014) Horizontal bone augmentation by means of guided bone regeneration. Periodontology 2000 66, 13-40. doi: $10.1111 /$ prd.12039.

Benic, G. I., Mokti, M., Chen, C. J., Weber, H. P., Hammerle, C. H. \& Gallucci, G. O. (2012) Dimensions of buccal bone and mucosa at immediately placed implants after 7 years: a clinical and cone beam computed tomography study. Clinical Oral Implants Research 23, 560-566. doi:10.1111/j.16000501.2011.02253.x.

Bornstein, M. M., Halbritter, S., Harnisch, H., Weber, H. P. \& Buser, D. (2008) A retrospective analysis of patients referred for implant placement to a specialty clinic: indications, surgical procedures, and early failures. International Journal of Oral and Maxillofacial Implants 23, 1109-1116.

Botticelli, D., Berglundh, T. \& Lindhe, J. (2004) Hard-tissue alterations following immediate implant placement in extraction sites. Journal of Clinical Periodontology 31, 820-828. doi:10.1111/j.1600-051X.2004.00565.x.

Buser, D., Ingimarsson, S., Dula, K., Lussi, A., Hirt, H. P. \& Belser, U. C. (2002) Long-term stability of osseointegrated implants in augmented bone: a 5year prospective study in partially edentulous patients. International Journal of Periodontics and Restorative Dentistry 22, 109-117.

Carbonell, J. M., Martin, I. S., Santos, A., Pujol, A., Sanz-Moliner, J. D. \& Nart, J. (2014) High-density polytetrafluoroethylene membranes in guided bone and tissue regeneration procedures: a literature review. International Journal of Oral and Maxillofacial Surgery 43, 75-84. doi:10.1016/j.ijom.2013.05.017.

Cardaropoli, G., Lekholm, U. \& Wennstrom, J. L. (2006) Tissue alterations at implant-supported single-tooth replacements: a 1-year prospective clinical study. Clinical Oral Implants Research 17, 165-171.

Chang, M., Wennstrom, J. L., Odman, P. \& Andersson, B. (1999) Implant supported single-tooth replacements compared to contralateral natural teeth. Crown and soft tissue dimensions. Clinical Oral Implants Research 10, 185-194.

Chiapasco, M. \& Zaniboni, M. (2009) Clinical outcomes of GBR procedures to correct peri-implant dehiscences and fenestrations: a systematic review. Clinical Oral Implants Research 20 Suppl 4, 113-123. doi: 10.1111/j.1600-0501.2009.01781.x.

Dahlin, C., Lekholm, U., Becker, W., Becker, B., Higuchi, K., Callens, A. \& van Steenberghe, D. (1995) Treatment of fenestration and dehiscence bone defects around oral implants using the guided tissue regeneration technique: a prospective multicenter study. International Journal of Oral and Maxillofacial Implants 10, 312-318.

Donos, N., Mardas, N. \& Chadha, V. (2008) Clinical outcomes of implants following lateral bone augmentation: systematic assessment of available options (barrier membranes, bone grafts, split osteotomy). Journal of Clinical Periodontology 35, 173-202. 
Esposito, M., Grusovin, M. G., Coulthard, P. \& Worthington, H. V. (2006) The efficacy of various bone augmentation procedures for dental implants: a Cochrane systematic review of randomized controlled clinical trials. International Journal of Oral and Maxillofacial Implants 21, 696-710.

Friedmann, A., Strietzel, F. P., Maretzki, B., Pitaru, S. \& Bernimoulin, J. P. (2001) Observations on a new collagen barrier membrane in 16 consecutively treated patients. Clinical and histological findings. Journal of Periodontology 72, 1616-1623. doi:10.1902/jop.2001.72.11.1616.

Friedmann, A., Strietzel, F. P., Maretzki, B., Pitaru, S. \& Bernimoulin, J. P. (2002) Histological assessment of augmented jaw bone utilizing a new collagen barrier membrane compared to a standard barrier membrane to protect a granular bone substitute material. Clinical Oral Implants Research 13, 587-594.

Gottlow, J., Nyman, S., Karring, T. \& Lindhe, J. (1984) New attachment formation as the result of controlled tissue regeneration. Journal of Clinical Periodontology 11, 494-503.

Gottlow, J., Nyman, S., Lindhe, J., Karring, T. \& Wennstrom, J. (1986) New attachment formation in the human periodontium by guided tissue regeneration. Case reports. Journal of Clinical Periodontology 13, 604616.

Grunder, U. (2000) Stability of the mucosal topography around single-tooth implants and adjacent teeth: 1-year results. International Journal of Periodontics and Restorative Dentistry 20, 11-17.

Hammerle, C. H., Bragger, U., Schmid, B. \& Lang, N. P. (1998) Successful bone formation at immediate transmucosal implants: a clinical report. International Journal of Oral and Maxillofacial Implants 13, 522-530.

Hammerle, C. H., Jung, R. E. \& Feloutzis, A. (2002) A systematic review of the survival of implants in bone sites augmented with barrier membranes (guided bone regeneration) in partially edentulous patients. Journal of Clinical Periodontology 29 Suppl 3, 226-231; discussion 232-223.

Hammerle, C. H. \& Karring, T. (1998) Guided bone regeneration at oral implant sites. Periodontology 2000 17, 151-175.

Hammerle, C. H. \& Lang, N. P. (2001) Single stage surgery combining transmucosal implant placement with guided bone regeneration and bioresorbable materials. Clinical Oral Implants Research 12, 9-18.

Hockers, T., Abensur, D., Valentini, P., Legrand, R. \& Hammerle, C. H. (1999) The combined use of bioresorbable membranes and xenografts or autografts in the treatment of bone defects around implants. A study in beagle dogs. Clinical Oral Implants Research 10, 487-498.

Jemt, T., Ahlberg, G., Henriksson, K. \& Bondevik, O. (2006) Changes of anterior clinical crown height in patients provided with single-implant restorations after more than 15 years of follow-up. International Journal of Prosthodontics 19, 455-461.

Jemt, T. \& Lekholm, U. (2003) Measurements of buccal tissue volumes at singleimplant restorations after local bone grafting in maxillas: a 3-year clinical prospective study case series. Clinical Implant Dentistry and Related Research 5, 63-70.

Jensen, S. S., Bosshardt, D. D., Gruber, R. \& Buser, D. (2014) Long-Term Stability of Contour Augmentation in the Esthetic Zone. Histologic and Histomorphometric Evaluation of 12 Human Biopsies 14 to 80 Months After Augmentation. Journal of Periodontology, 1-15. doi: $10.1902 /$ jop.2014.140182.

Jensen, S. S. \& Terheyden, H. (2009) Bone augmentation procedures in localized defects in the alveolar ridge: clinical results with different bone grafts and bone-substitute materials. International Journal of Oral and Maxillofacial Implants 24 Suppl, 218-236. 
Jovanovic, S. A., Spiekermann, H. \& Richter, E. J. (1992) Bone regeneration around titanium dental implants in dehisced defect sites: a clinical study. International Journal of Oral and Maxillofacial Implants 7, 233-245.

Jung, R. E., Fenner, N., Hammerle, C. H. \& Zitzmann, N. U. (2013) Long-term outcome of implants placed with guided bone regeneration (GBR) using resorbable and non-resorbable membranes after $12-14$ years. Clinical Oral Implants Research 24, 1065-1073. doi:10.1111/j.16000501.2012.02522.x.

Jung, R. E., Glauser, R., Scharer, P., Hammerle, C. H., Sailer, H. F. \& Weber, F. E. (2003) Effect of rhBMP-2 on guided bone regeneration in humans. Clinical Oral Implants Research 14, 556-568.

Jung, R. E., Halg, G. A., Thoma, D. S. \& Hammerle, C. H. (2009) A randomized, controlled clinical trial to evaluate a new membrane for guided bone regeneration around dental implants. Clinical Oral Implants Research 20, 162-168. doi:10.1111/j.1600-0501.2008.01634.x.

Karring, T., Nyman, S., Gottlow, J. \& Laurell, L. (1993) Development of the biological concept of guided tissue regeneration--animal and human studies. Periodontology 2000 1, 26-35.

Kuchler, U., Chappuis, V., Gruber, R., Lang, N. P. \& Salvi, G. E. (2015) Immediate implant placement with simultaneous guided bone regeneration in the esthetic zone: 10 -year clinical and radiographic outcomes. Clinical Oral Implants Research. doi:10.1111/clr.12586.

Moses, O., Pitaru, S., Artzi, Z. \& Nemcovsky, C. E. (2005) Healing of dehiscencetype defects in implants placed together with different barrier membranes: a comparative clinical study. Clinical Oral Implants Research 16, 210-219.

Nyman, S., Lindhe, J., Karring, T. \& Rylander, H. (1982) New attachment following surgical treatment of human periodontal disease. Journal of Clinical Periodontology 9, 290-296.

O'Leary, T. J., Drake, R. B. \& Naylor, J. E. (1972) The plaque control record. Journal of Periodontology 43, 38. doi:10.1902/jop.1972.43.1.38.

Piette, E., Alberius, P., Samman, N. \& Linde, A. (1995) Experience with e-PTFE membrane application to bone grafting of cleft maxilla. International Journal of Oral and Maxillofacial Surgery 24, 327-332.

Pitaru, S., Tal, H., Soldinger, M., Azar-Avidan, O. \& Noff, M. (1987) Collagen membranes prevent the apical migration of epithelium during periodontal wound healing. Journal of Periodontal Research 22, 331-333.

Priest, G. (2003) Predictability of soft tissue form around single-tooth implant restorations. International Journal of Periodontics and Restorative Dentistry 23, 19-27.

Schneider, D., Grunder, U., Ender, A., Hammerle, C. H. \& Jung, R. E. (2011) Volume gain and stability of peri-implant tissue following bone and soft tissue augmentation: 1-year results from a prospective cohort study. Clinical Oral Implants Research 22, 28-37. doi:10.1111/j.16000501.2010.01987.x.

Schneider, D., Schmidlin, P. R., Philipp, A., Annen, B. M., Ronay, V., Hammerle, C. H., Attin, T. \& Jung, R. E. (2014) Labial soft tissue volume evaluation of different techniques for ridge preservation after tooth extraction: a randomized controlled clinical trial. Journal of Clinical Periodontology 41, 612-617. doi:10.1111/jcpe.12246.

Seibert, J. S. (1983) Reconstruction of deformed, partially edentulous ridges, using full thickness onlay grafts. Part I. Technique and wound healing. Compendium of Continuing Education in Dentistry 4, 437-453.

Simion, M., Baldoni, M., Rossi, P. \& Zaffe, D. (1994) A comparative study of the effectiveness of e-PTFE membranes with and without early exposure during the healing period. International Journal of Periodontics and Restorative Dentistry 14, 166-180. 
Spray, J. R., Black, C. G., Morris, H. F. \& Ochi, S. (2000) The influence of bone thickness on facial marginal bone response: stage 1 placement through stage 2 uncovering. Annals of Periodontology 5, 119-128. doi:10.1902/annals.2000.5.1.119.

Strietzel, F. P. (2001) [Risks and complications of membrane-guided bone regeneration. Retrospective analysis]. Mund-, Kiefer- und Gesichtschirurgie 5, 28-32.

Strietzel, F. P., Khongkhunthian, P., Khattiya, R., Patchanee, P. \& Reichart, P. A. (2006) Healing pattern of bone defects covered by different membrane types--a histologic study in the porcine mandible. Journal of biomedical materials research. Part B, Applied biomaterials 78, 35-46. doi:10.1002/jbm.b.30452.

Thoma, D. S., Zeltner, M., Hilbe, M., Hammerle, C. H., Husler, J. \& Jung, R. E. (2016) Randomized controlled clinical study evaluating effectiveness and safety of a volume-stable collagen matrix compared to autogenous connective tissue grafts for soft tissue augmentation at implant sites. Journal of Clinical Periodontology. doi:10.1111/jcpe.12588.

von Arx, T., Cochran, D. L., Hermann, J. S., Schenk, R. K., Higginbottom, F. L. \& Buser, D. (2001) Lateral ridge augmentation and implant placement: an experimental study evaluating implant osseointegration in different augmentation materials in the canine mandible. International Journal of Oral and Maxillofacial Implants 16, 343-354.

Wiltfang, J., Merten, H. A. \& Peters, J. H. (1998) Comparative study of guided bone regeneration using absorbable and permanent barrier membranes: a histologic report. International Journal of Oral and Maxillofacial Implants 13, 416-421.

Zitzmann, N. U., Naef, R. \& Scharer, P. (1997) Resorbable versus nonresorbable membranes in combination with Bio-Oss for guided bone regeneration. International Journal of Oral and Maxillofacial Implants 12, 844-852.

Zitzmann, N. U., Scharer, P. \& Marinello, C. P. (2001a) Long-term results of implants treated with guided bone regeneration: a 5-year prospective study. International Journal of Oral and Maxillofacial Implants 16, 355366.

Zitzmann, N. U., Scharer, P., Marinello, C. P., Schupbach, P. \& Berglundh, T. (2001b) Alveolar ridge augmentation with Bio-Oss: a histologic study in humans. International Journal of Periodontics and Restorative Dentistry 21, 288-295. 


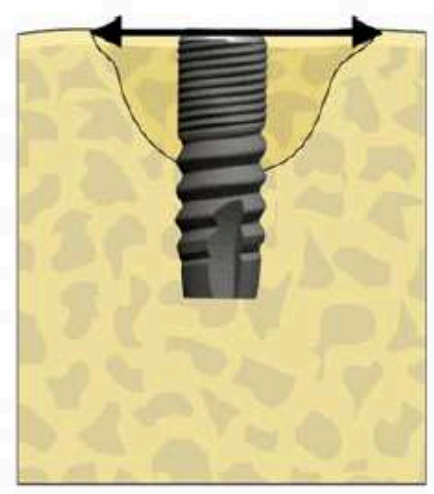

Defect width $(\mathrm{mm})$

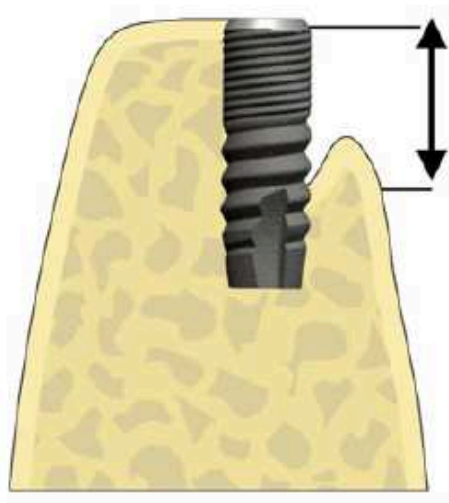

Vertical defect height $(\mathrm{mm})$

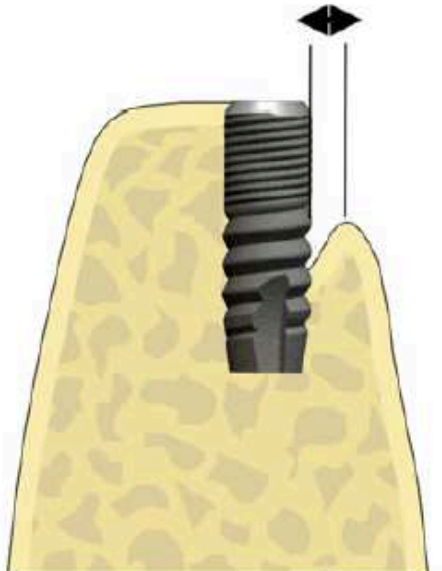

Defect depth (mm)

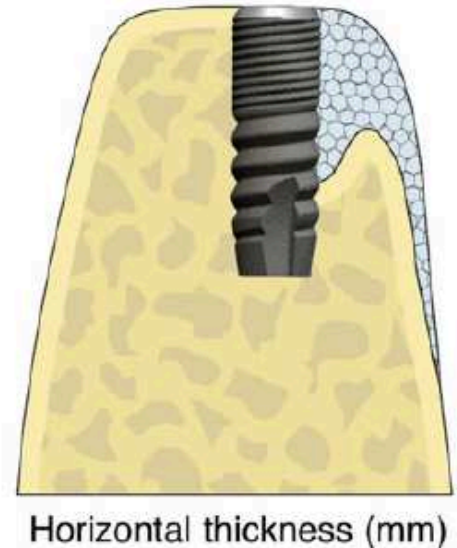

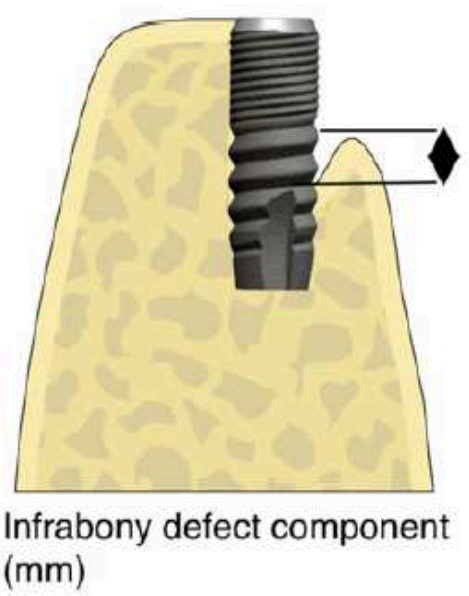

Figure 1

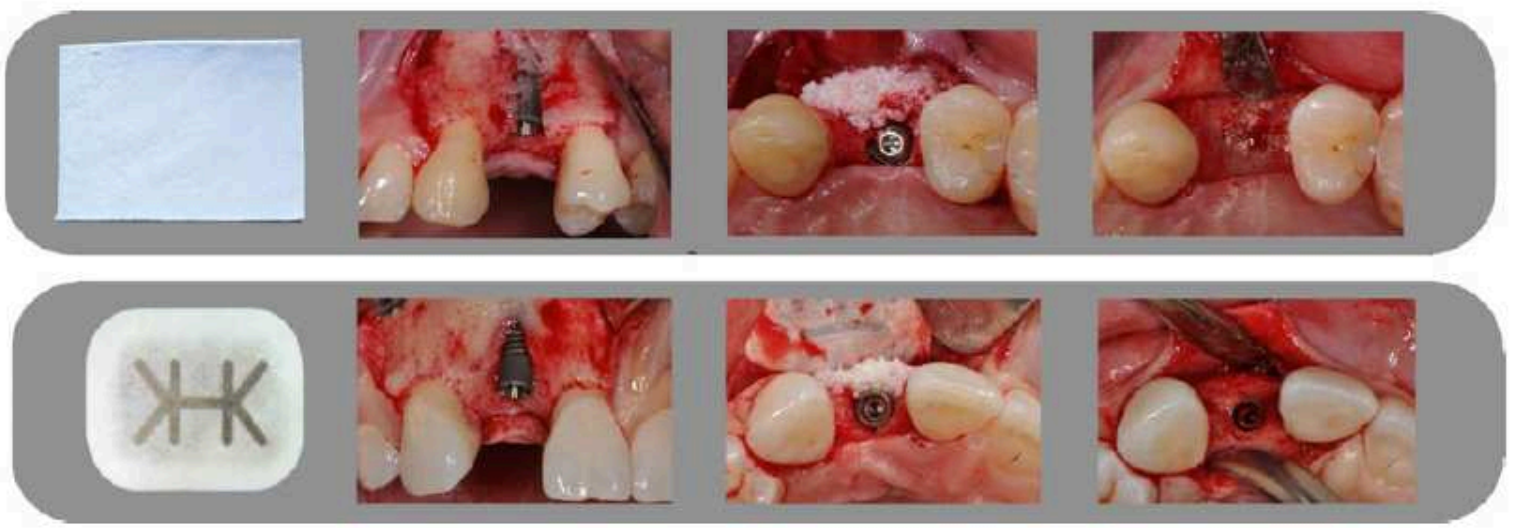

Figure 2 


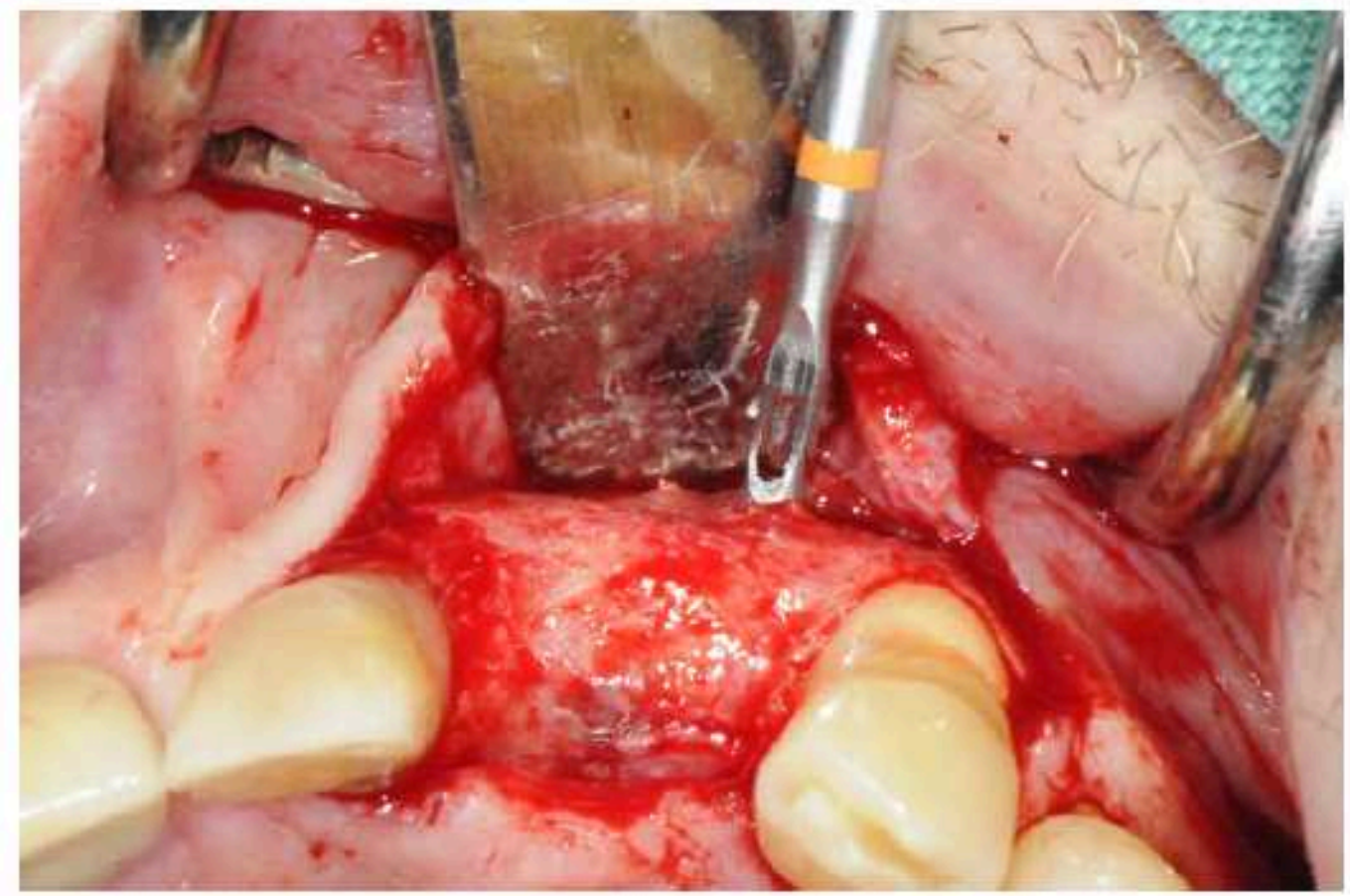

Figure 3

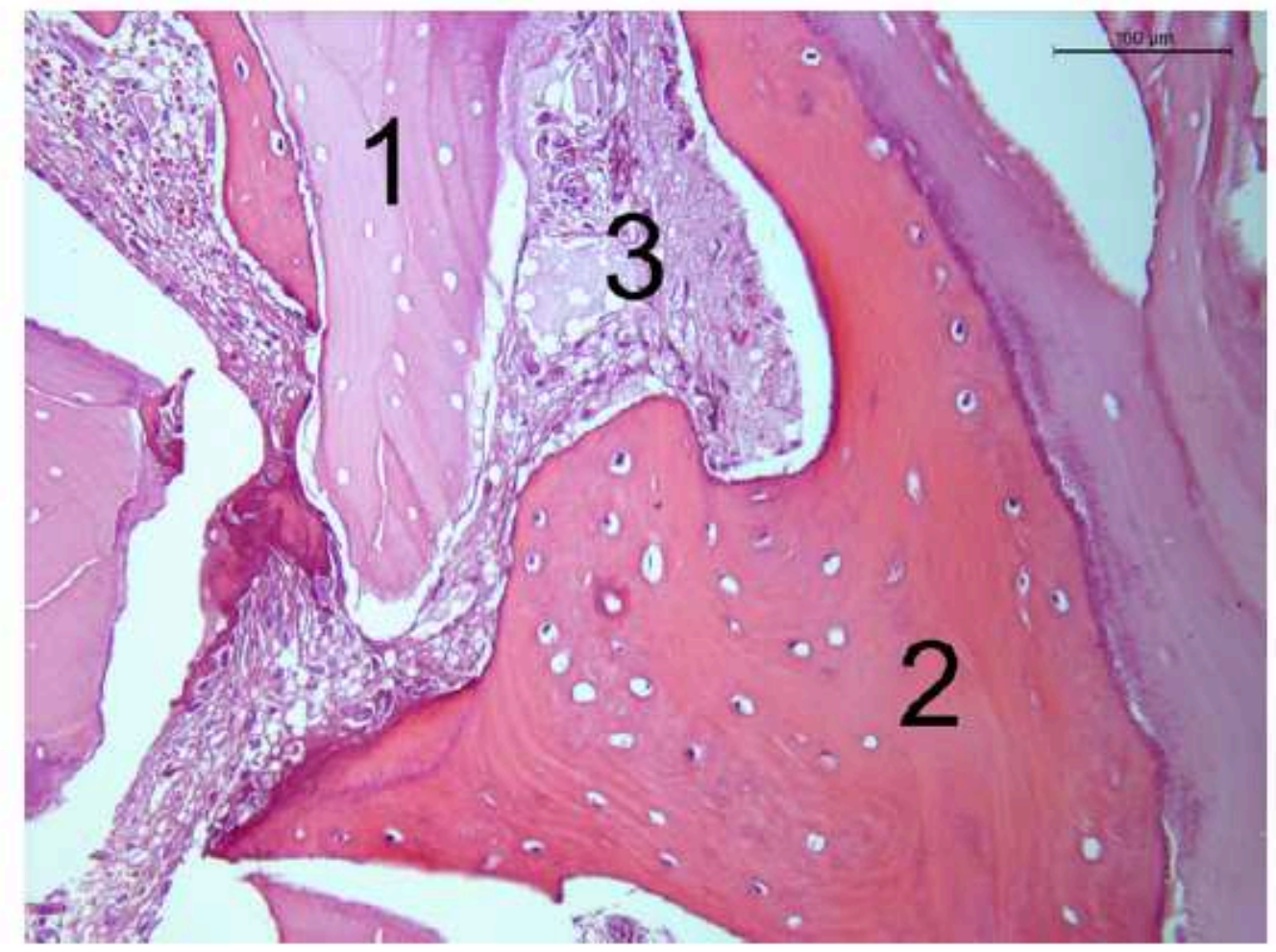

Figure 4 

Table 1

\begin{tabular}{|c|c|c|c|}
\hline & upper jaw (RES/N-RES) & lower jaw (RES/N-RES) & total \\
\hline central incisors & $4(2 / 2)$ & 0 & 4 \\
\hline lateral incisors & $8(1 / 7)$ & 0 & 8 \\
\hline premolars & $9(9 / 0)$ & $6(4 / 2)$ & 15 \\
\hline total & 21 & 6 & 27 \\
\hline
\end{tabular}

Table 2a

\begin{tabular}{|c|c|c|c|c|c|c|}
\hline \multicolumn{3}{|c|}{ At Surgery } & \multicolumn{4}{|c|}{ At Re-entry (6m) } \\
\hline & RES & N-RES & RES & N-RES & $\mathbf{p}-\mathbf{v}$ & \\
\hline Defect dimensions & & & & & time & group \\
\hline Width & $\begin{array}{c}3.08 \\
( \pm 0.18) \\
3.00\end{array}$ & $\begin{array}{c}3.19 \\
( \pm 0.33) \\
3.00\end{array}$ & $\begin{array}{c}0.73 \\
( \pm 0.33) \\
.00\end{array}$ & $\begin{array}{c}0.23 \\
( \pm 0.23) \\
.00\end{array}$ & $p=0.0001$ & $p=0.36$ \\
\hline Depth & $\begin{array}{c}0.92 \\
( \pm 0.23) \\
1.00\end{array}$ & $\begin{array}{c}1.00 \\
( \pm 0.28) \\
.00\end{array}$ & $\begin{array}{c}0.41 \\
( \pm 0.28) \\
.00\end{array}$ & $\begin{array}{c}0.23 \\
( \pm 0.23) \\
.00\end{array}$ & $p=0.003$ & $p=0.75$ \\
\hline Infrabony & $\begin{array}{c}0.15 \\
( \pm 0.15) \\
.00\end{array}$ & $\begin{array}{c}1.00 \\
( \pm 0.59) \\
.00\end{array}$ & $\begin{array}{c}0.0( \pm 0.0) \\
.00\end{array}$ & $\begin{array}{c}0.0( \pm 0.0) \\
.00\end{array}$ & $p=0.02$ & \\
\hline
\end{tabular}

Table 2b

\begin{tabular}{|c|c|c|c|}
\hline \multicolumn{4}{|c|}{ At Surgery } \\
\hline & RES & N-RES & p-value \\
\hline \multicolumn{4}{|l|}{$\begin{array}{l}\text { Vertical \& Horizontal } \\
\text { Dimensions }\end{array}$} \\
\hline $\begin{array}{l}\text { Vertical defect } \\
\text { median }\end{array}$ & $\begin{array}{c}4.00( \pm 2.07) \\
4.00\end{array}$ & $\begin{array}{c}2.36( \pm 2.09) \\
2.50\end{array}$ & $p=0.0444$ \\
\hline $\begin{array}{l}\text { Horizontal thickness } \\
\text { median }\end{array}$ & $\begin{array}{c}3.46( \pm 0.52) \\
3.00\end{array}$ & $\begin{array}{c}2.82( \pm 0.50) \\
3.00\end{array}$ & $p=0.0040$ \\
\hline
\end{tabular}


Table 2c

At Re-entry

(6months)

\begin{tabular}{|l|c|c|c|}
\hline \multicolumn{2}{|c|}{ RES } & N-RES & p-value \\
\hline Defect dimensions & & & \\
\hline $\begin{array}{l}\text { Vertical defect } \\
\text { median }\end{array}$ & $\begin{array}{c}0.77( \pm 0.85) \\
1.00\end{array}$ & $\begin{array}{c}0.21( \pm 0.80) \\
0.00\end{array}$ & $\mathrm{p}=0.0213$ \\
\hline $\begin{array}{l}\text { Horizontal thickness } \\
\text { median }\end{array}$ & $\begin{array}{c}1.32( \pm 1.38) \\
1.00\end{array}$ & $\begin{array}{c}2.68( \pm 1.05) \\
3.00\end{array}$ & $\mathrm{p}=0.0167$ \\
\hline $\begin{array}{l}\text { Loss of vertical defect } \\
\text { median }\end{array}$ & $\begin{array}{c}3.41( \pm 2.33) \\
4.00\end{array}$ & $\begin{array}{c}2.14( \pm 2.06) \\
2.00\end{array}$ & $\mathrm{p}=0.1069$ \\
\hline $\begin{array}{l}\text { Loss of horizontal } \\
\text { thickness } \\
\text { median }\end{array}$ & $2.23( \pm 1.21)$ & $\begin{array}{c}0.14( \pm 0.79) \\
0.00\end{array}$ & $\mathrm{p}=0.0001$ \\
\hline
\end{tabular}


Table 3a

\begin{tabular}{|c|c|c|c|c|}
\hline & $\begin{array}{c}1 \text { week } \\
\text { (suture removal) }\end{array}$ & 4 weeks & 3 months & $\begin{array}{l}\text { At Re-entry } \\
\text { (6 months) }\end{array}$ \\
\hline RES & 4 & 0 & 0 & 0 \\
\hline N-RES & 1 & 2 & 1 & 1 \\
\hline
\end{tabular}

Table 3b

\begin{tabular}{|c|c|c|c|}
\hline & normal (e.g. healthy) & red/swollen & dehiscence \\
\hline RES & 6 & 2 & 0 \\
\hline N-RES & 7 & 5 & 1 \\
\hline percentage & $50.5 \%$ & $25.9 \%$ & $7.7 \%$ \\
\hline
\end{tabular}

